\title{
College Achievement Among Native Americans: A Research Note*
}

\author{
H A R O L D R . KE R B O, California Polytechnic State University, \\ San Luis Obispo
}

Since 1960 there has been a rapid increase in the number of Native Americans attending college; but the rate of completion has been less than half that of whites. The research reported in this note begins an inquiry into the reasons for the lower rate of college success, indexed by GPA, among Native Americans than among their counterpart whites.

Although empirical studies of college success among Native Americans are few, there has been some speculation (and a little empirical work) on their performance in the lower grades. In common with other racial and ethnic groups, low family SES, school quality, educational aspirations, and the racial mixture of primary and secondary schools attended have been related to educational success. But most measures of school quality have been found unimportant; and family SES has not been so effective a predictor at the college level as for the earlier years of schooling.

In contrast to other racial or ethnic groups, however, the literature on Native American educational attainment has stressed cultural factors most heavily. The present research attempts to empirically test for the importance of these cultural factors, along with other aspects related to the general concept of assimilation/acculturation among Native Americans.

\section{Sample}

The sample consisted of 253 individuals, of whom 102 were Native Americans and 151 whites, attending universities in the state of Oklahoma in 1978. ${ }^{1}$ The white sample was obtained by distributing the questionnaire in six social science classes at two universities. In order to obtain an adequate

\footnotetext{
*Data analysis was partially funded through a research grant from California Polytechnic State University (\# 2623.31). I would like to thank Sara Pawlan, Robert Quan, and especially Walter Lamar for their help and comments. Also I would like to thank Marcia Dunklau, Diane Goldman, and Patricia Tupac-Yupanqui for their typing and editorial comments.
}

- 1981 The University of North Carolina Press. 0037-7732/81/041275-80\$00.60 
sample of Native American college students, the study relied primarily on the help of Native American counselors employed at four universities. They were asked to administer the questionnaire within a period of two months to Native American college students they came in contact with through group meetings or routine office visits.

In an attempt to detect any bias in sample collection, the major variables in the study were compared across the four universities where the Native American sample was obtained. In addition, a small number of 23 Native American students were given the questionnaire in classes from which we obtained the white sample. In only the cases of tribal enrollment and socioeconomic level (in one university) did the five subsamples of Native American college students show significant differences. The overall sample showed no significant differences between whites and Native Americans on sex, age, college level, or hometown population size.

\section{Measurement of Primary Variables}

A typical measure of college success, students' GPA, was obtained through self-reported cumulative GPA since entering college (on a scale ranging from 4.0 to 0.0 ). Also included were the students' self-reported high school cumulative GPA and college entrance exam scores (ACT test scores). Two items measuring parents' "urging college attendance" and taking such attendance "for granted" were indicators of parents' educational aspirations for their children. And to estimate their motivation for occupational success in a general sense, Kahl's scale of "Occupational Primacy" was used.

One of the most important cultural differences said to influence educational success among Native Americans is the existence of values rejecting individual competition. Four items were constructed specifically relating this supposed value to educational competition among friends. In order to test for the suggested effects of assimilation and social integration more generally, items were included indicating racial identity, identity conflict, degree of Native American blood (amalgamation), and degree of interaction with whites (social integration). Items were also included attempting to indicate closeness to the traditional Native American culture by measuring knowledge of a Native American language, having lived-or having parents who lived-on an Indian reservation. But only the item asking if the students' parents had lived on an Indian reservation showed sufficient variance to be included in the analysis. Finally, as an indicator of white contact in the early years of schooling, we ask the percent who were Native American in the primary high school attended. 


\section{Findings}

Consistent with previous research involving primarily white college students, high school GPA shows the strongest zero-order relationship to college GPA in our total sample $(r=.395$, complete zero-order correlations not included in this research note). But it is important to note that the dummy variable, race (White/Native American) shows the next strongest relation to college GPA $(r=.374)$, closely behind high school GPA, and ahead of the relation between college GPA and entrance exam scores $(r=$ .336). As with previous research on the college level, only a weak relation is found between college GPA and father's occupation $(r=.178)$. Kahl's achievement orientation scale also shows a weak relation to college GPA $(r=.173)$. Of several independent variables, excluding the cultural and assimilation items discussed below, the above are the only ones found significantly related to college GPA at the .01 level.

To assess the independent effect of race on college GPA, stepwise multiple regression was employed. Table 1 shows that among the noncultural/assimilation variables, the dummy variable of race continues to show the second strongest relation to college GPA. Considered together, of course, the independent variables listed in Table 1 account for only about one-quarter of the variance in college GPA. But this multiple $R^{2}$ of .252 does show improvement over the usual multiple of $R^{2}$ of about .10 to .20 in numerous previous studies. Thus, adding the effects related to racial differences must be considered as an improvement.

Our next question must be: What is it about race (White/Native American) that results in lower college success (GPA)? The data have led us to reject educational aspirations as an answer $(r=.073$ for Native Americans). As noted above, the Native American rejection of individual competition has been suggested as a factor in low educational attainment.

Table 1. STEPWISE MULTIPLE REGRESSION: PREDICTORS OF COLLEGE GPA AMONG TOTAL SAMPLE

\begin{tabular}{llll}
\hline & \multicolumn{1}{c}{$\begin{array}{c}\text { Multiple } \\
\mathrm{R}\end{array}$} & $\begin{array}{c}\text { Multiple } \\
\mathrm{R}^{2}\end{array}$ & $\begin{array}{c}\text { Change in } \\
\mathrm{R}^{2}\end{array}$ \\
\hline (1) High school GPA & $.395(.395) *$ & .156 &. \\
(2) Race & $.464(.374) *$ & .215 & .059 \\
(3) ACT scores & $.486(.336) *$ & .237 & .022 \\
(4) Parents urged college & $.493(.106)$ & .244 & .007 \\
(5) Father's occupation & $.496(.178) *$ & .246 & .002 \\
(6) Size of home town & $.501(.052)$ & .251 & .005 \\
(7) Father's education & $.502(.125)$ & .252 & .001 \\
(8) College taken for granted & $.502(.123)$ & .252 & .000 \\
\hline
\end{tabular}

*Zero-order correlations to college GPA significant at the .01 level. 
However, the data lead us to reject this possibility also. Our four measures of individual competition (or rejection of such competition) are not significantly related to college GPA, among the total sample, or with either whites and Native Americans considered separately (with Native Americans these four ranged from $r=.035$ to .143 ). In fact, none of these four items shows a significant relationship (at the .01 level) to race. Thus, if these four items are valid measures of individual competition (or a rejection of such competition), we cannot even conclude that Native American college students differ from white college students on this value.

We have yet to consider various assimilation measures suggested in some of the recent literature. The next step in our analysis will focus on Native Americans exclusively in order to examine the impact of these variables on college success. At the outset it should be noted that a dummy variable, "tribe," was weakly related to college GPA; Plains and "Civilized" tribes vs. "other tribes" (mostly southwest tribes such as Navajo, Zuni, etc.) did show a weak relation to college GPA ( $r=.197)$ Thus, because this "other" category may in some unmeasured way affect other variables (given that these tribes are poorly represented in Oklahoma), and because only 19 individuals in our Native American sample fall into this "other" tribal category, this part of our sample has been dropped from the analysis.

Employing stepwise multiple regression to examine the independent effect of several variables with our sample of Native Americans only, we find that racial identity is the best predictor of college GPA (see Table 2). High school GPA enters the model in second position, while ACT scores enter in the fifth position. Degree of white blood and number of white friends enter in the third and fourth positions. Overall we find a multiple $R$ of .442, and a multiple $R^{2}$ of .196 .

Table 2. STEPWISE MULTIPLE REGRESSION: PREDICTORS OF COLLEGE GPA FOR NATIVE AMERICANS*

\begin{tabular}{llll}
\hline & $\begin{array}{c}\text { Multiple } \\
R\end{array}$ & $\begin{array}{c}\text { Multiple } \\
R^{2}\end{array}$ & $\begin{array}{c}\text { Change in } \\
R^{2}\end{array}$ \\
\hline (1) Racial 10 & $.323(.323) \star *$ & .104 &. \\
(2) High school GPA & $.387(.272) \star *$ & .150 & .046 \\
(3) Percent white blood & $.405(.366) \star *$ & .164 & .014 \\
(4) Number of white friends & $.415(.255) \star *$ & .172 & .008 \\
(5) ACT scores & $.428(.116)$ & .184 & .012 \\
(6) Percent whites in high school & $.440(.111)$ & .194 & .010 \\
(7) Parents from reservation & $.442(.119)$ & .195 & .001 \\
(8) 1D conflict & $.442(-.046)$ & .196 & .001 \\
\hline
\end{tabular}

*For the reduced sample of Native Americans, $N=83$.

$\star \star Z$ ero order correlations to college GPA significant at the .01 level. 
Native Americans' Achievement / 1279

\section{Social Integration, Identity, and Achievement}

As noted above, several studies (including numerous independent variables) explain no more than 10 to 20 percent of the variance in college GPA among mostly white college students. Our analysis has not improved on this prediction rate among Native American college students. But most importantly, our data suggest that the best predictors of college GPA differ when considering Native American rather than white college students. The best independent predictors of college success among Native Americans fall under the general condition of degree of identification and social integration with whites (with the exception of high school GPA in second position and percent white blood in third position, see Table 2). However, it does not appear that it is overall assimilation or acculturation that best explains Native American college success. Native Americans did show slightly lower educational aspirations $(r=.154)$, but this was not found significantly related to college GPA $(r=.073)$. And perhaps more important, cultural factors suggested as most important in the literature (such as a rejection of individual competition) were not found related to either race (white versus Native Americans) or college GPA. If it is not overall assimilation or acculturation that helps us understand college success among Native Americans, what then do the data suggest? What is it about racial identification and social integration with whites that leads to a higher rate of college success?

From studies of young children showing the importance of selfconfidence and racial integration (when it leads to social integration) for educational achievement, we can speculate as to the meaning of our findings on college success among Native Americans. When Native Americans come to identify themselves as more white, and at the same time more often interact with whites (e.g., have more white friends), they may come to feel more accepted in the college environment. In essence, they come to feel that they fit in with whites and white institutions (a relationship to racial identification among Native Americans found in a previous study). When this feeling of fitting in is achieved, Native American students may come to feel that they equal whites in ability to perform in college. Thus, a contextual definition of the self is achieved which leads to better college performance. It is not valuing education more that is important, or other acculturation factors, but simply the confidence in one's ability to achieve something that may also be highly valued by all (or most) Native American college students. And finally, it is important to note that this explanation of our findings suggests that we need no special or unique set of variables to understand academic achievement or failure among Native Americans. This process of social integration and a definition of the self (as one who 
can compete equally with others) may be common among all groups found toward the bottom of the stratification system.

In concluding, it must be stressed that our interpretation of the findings should be seen as highly speculative at this time. Of course, more research with Native American students (as well as other minority groups) is needed; and more specific measures relating self-confidence, racial identity, social integration with the dominant group, and academic performance must be included in this research. However, the present research does seriously question the importance of cultural values as a main factor in academic success among Native Americans, at least at the college level.

\section{Note}

1. Due to the condensed nature of this research note the author will be pleased to send fuller information on any aspect of this study to any fellow social scientist who has a professional interest in such research. Send inquiries to: Harold R. Kerbo, Department of Social Sciences, California Polytechnic State University, San Luis Obispo, California, 93407. 